\title{
Sirtuins in Skin and Skin Cancers
}

\author{
Liz Mariely Garcia-Peterson $^{a} \quad$ Melissa Jean Wilking-Busch ${ }^{a} \quad$ Mary Ann Ndiaye $^{a}$ \\ Christine Gaby Azer Philippe ${ }^{a}$ Vijayasaradhi Setaluria, ${ }^{a}$ Nihal Ahmad ${ }^{a}$ b

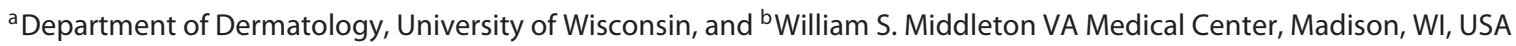

\section{Keywords}

Sirtuins $\cdot$ Skin $\cdot$ Histone deacetylases

\section{Abstract}

The sirtuins are a family of proteins that comprise class III of the histone deacetylases. These NAD+-dependent proteins have been found to be intricately involved in a variety of important and skin-relevant cellular functions and processes, including aging, UV damage response, oxidative stress, and wound repair. In addition, recent research is unraveling the role of sirtuins in a variety of skin diseases, including melanoma and nonmelanoma skin cancers. In this review, we provide a discussion on the potential roles and implications of different sirtuins in skin-specific cellular processes, which may have relevance to skin health and skin diseases. Based on the available literature, the sirtuins appear to be important targets in the management of a variety of skin diseases from cosmetic (e.g., skin aging) to fatal conditions (e.g., melanoma).

(c) 2017 S. Karger AG, Basel
\end{abstract}

Liz Mariely Garcia-Peterson and Melissa Jean Wilking-Busch contributed equally to this work.

\section{KARGER}

(C) 2017 S. Karger AG, Basel

E-Mail karger@karger.com

www.karger.com/spp

\section{Introduction}

Sirtuins (SIRTs) comprise 1 of 4 classes of histone deacetylases (HDACs; I-IV) that play important roles in a variety of cellular functions. This class III of HDACs is entirely dedicated to the SIRTs, based on their homology to the yeast protein SIR2 (silent information regulator 2), their conserved catalytic domain, and nicotinamide adenine dinucleotide $(\mathrm{NAD}+)$ dependence $[1,2]$. Seven members of the sirtuin family (SIRTs 1-7) have been identified so far. Although their core domain is conserved, they differ in their $\mathrm{N}$ - and C-terminal domains (Fig. 1) [3]. SIRTs are evolutionarily conserved from prokaryotic through eukaryotic cells, and although they are classified as HDACs, the family is responsible for several types of posttranslational modifications in both histone and nonhistone proteins, which are important for a variety of cellular processes. Some of the nondeacetylase activities for each sirtuin are outlined in Figure 1. Additionally, despite structural similarities, each sirtuin has its own biological niche, performing unique functions via regulating critical mechanisms in the cell.

As an indication of the different roles they play biologically, the different sirtuin members have been found to be located in relatively discrete cellular compartments

Nihal Ahmad, PhD

Department of Dermatology, University of Wisconsin Medical Science Center 1300 University Avenue

Madison, WI 53706 (USA)

E-Mail nahmad@wisc.edu 
Fig. 1. Sirtuin function and localization. A visual representation of the 7 mammalian sirtuins. Relative size and nondeacetylation activities are shown, as well as subcellular location. SIRTs 1 and 2 function in both the nucleus and cytoplasm, with SIRT1 showing more nuclear functions and SIRT2 more cytoplasmic ones. SIRT6 is found in the nucleus, and SIRT7 is associated with the nucleolus, while SIRTs 3-5 are primarily mitochondrial. Dark blue bands represent the conserved core catalytic domains while surrounding bands indicate the $\mathrm{N}$ and C-terminal regions of each sirtuin. References for the nondeacetylation activities are as follows: (1) [87]; (2) [88]; (3) [89]; (4) [90]; (5) [91]; (6) [92]; (7) [93]; (8) [94]; (9) [95]; (10) [96].

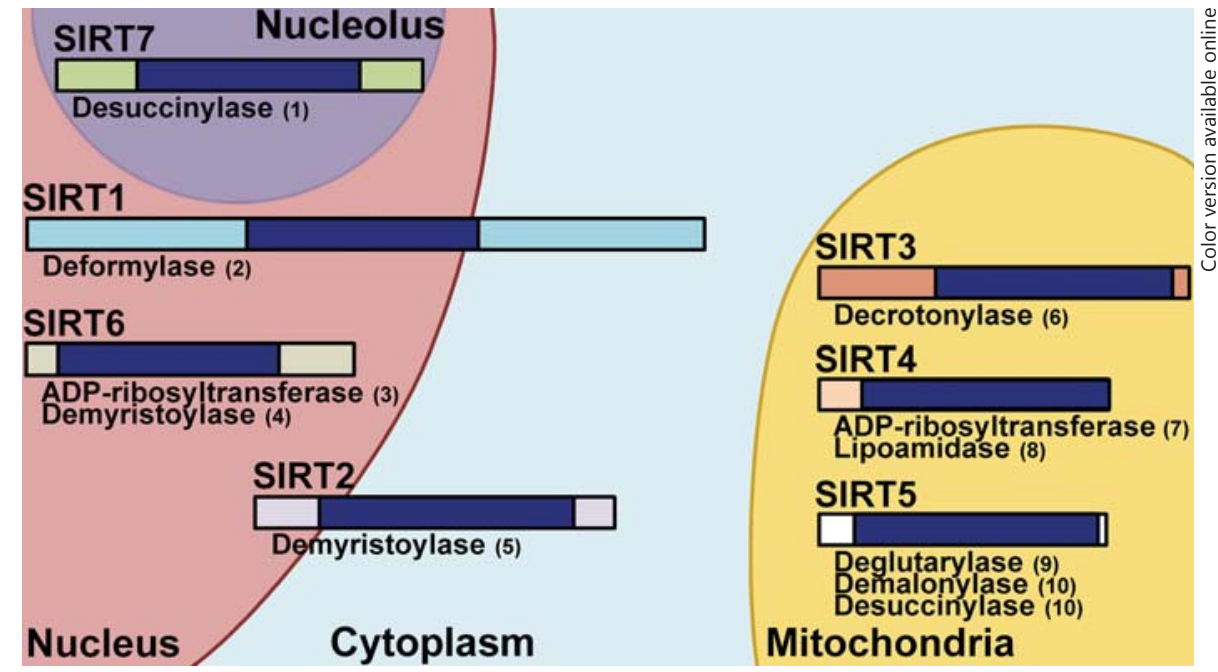

(shown in Fig. 1). For example, SIRTs 1, 6, and 7 are located mostly in the nucleus, consistent with their roles in transcription facilitation and epigenetic regulation [4]. SIRT2 is found mainly in the cytoplasm, enabling it to interact with proteins involved in gluconeogenesis, the immune and inflammatory response, and microtubule stabilization [5, 6]. SIRTs 3,4 , and 5 are most commonly found within the mitochondria, which is in accordance with their importance in cellular metabolism (reviewed in Michan and Sinclair [7]). Interestingly, some of these sirtuins have been shown to be both nuclear and cytoplasmic, suggesting nuclear-cytoplasmic shuttling, and intracellular locations and roles which could be dependent on tissue and cell type (discussed in Haigis and Guarrente [8]).

While the roles of sirtuins have been explored extensively in other systems, their roles in the skin and skin cancers are less well defined (discussed in Serravallo et al. [9]). Here, we discuss the function of sirtuins in the skin as it pertains to aging, ultraviolet (UV) radiation damage, and oxidative stress, as well as several skin diseases, with an emphasis on skin cancers.

\section{The Skin and the Impact of Sirtuins on Chronological Aging}

As the largest organ in the body, the skin performs many different and vital functions. Through its complex structure, it acts to both protect the body from damage as well as to provide a surface for external interactions. The functions of the skin range from simple barrier activities to complex endocrine signaling and biomolecule synthesis activities [10]. Damage to the skin can disrupt or alter its ability to fulfill these crucial roles and can come in many forms, including environmental stresses and physical injuries, and can even be exacerbated by psychosocial stress $[10,11]$. Each of these stressors can have different effects on the skin, and some may not show any visible effects for a long time, such as damage from UV exposure and oxidative stress. To complicate matters, some potentially damaging agents like UV radiation may actually be beneficial or even essential to a healthy body when used in moderation (discussed in Holick [12]). To maintain the necessary balance of protection and selective penetrance, the skin must tightly regulate its activities via a complex network of cells, nerves, chemicals, and lipids that are structured in a way to best accomplish its varied roles.

Keratinocytes, melanocytes, Langerhans cells, and Merkel cells make up the majority of the cells in the skin. The importance of each of these cells, along with the structure, function, and key molecules present in the skin, are discussed in depth and explained in an article on the integumentary system by McLafferty et al. [10]. Briefly, the skin consists of a series of layers, ranging from the external epidermis to the dermis. The outermost layer of the skin, the epidermis, consists mainly of keratinocytes and is responsible for the bulk of its barrier functions (reviewed in Boer et al. [13]). Underneath the epidermis is the dermis. This layer contains the structural and nutritive components necessary to support a healthy epidermis, as well as the various vessels, glands, and nerves that make the skin so complex [10]. The close proximity of the 
skin to the environment facilitates aging, cellular, and tissue damage, wounds, and diseases, all of which appear to be linked to the sirtuins.

From the time of their discovery, the sirtuins have been implicated in the process of aging. Preceding their identification in mammals, lifespan extension via caloric restriction was widely studied as one of the primary functions of the yeast homolog protein Sir2 (reviewed in Sinclair [14]). It was initially thought that this would translate to mammals, and although many reports have found similar results, several other studies have found no effects of sirtuins on lifespan [15-20]. There was more consistent success when using small molecule activators, but initial successes, as with some of the initial yeast and fly studies [21], were likely due to off-target effects [22, 23]. Thus, the final verdict on the ability of sirtuins to directly affect aging remains an ongoing quest (reviewed in Kanfi et al. [19] and Dang [24]). However, beyond direct effects, sirtuins have been found to interact with other major longevity factors, including AMP-activated protein kinase, phosphatidylinositol-3-OH kinase, insulin-like growth factor 1 , and mechanistic target of rapamycin (reviewed in Thandavarayan et al. [25]). Indeed, the process of aging itself is still not clearly understood and includes aspects of lifespan, cellular changes (such as apoptosis, protein modifications, and increased senescence), and cosmetic changes. Prevalent theories for these changes include decreased telomere length from repeated cell division, exhaustion of a limited neuronal or stem cell population, accumulation of cellular toxins over time, or repeated DNA damage from environmental stresses [2629]. Because of findings supporting their role in longevity, there is abundant evidence regarding the link between sirtuins and aging throughout the body (reviewed in Watroba and Szukiewicz [30]).

In the skin, the physical characteristics associated with aging are visually apparent. Aged skin becomes thin and shows an increase in wrinkles, as well as a decrease in hydration and skin elasticity $[31,32]$. Interestingly, researchers have found that several sirtuins have a changed expression profile depending on the age of the person or cell line being studied. For example, a 2014 study found that SIRT1 levels decreased with age in dermal fibroblasts isolated from female donors who ranged from 20 to 67 years old [33]. Another study found that both SIRT1 and SIRT6 levels decreased in human dermal fibroblasts with higher passage numbers, and that these levels were associated with aging biomarkers found in the same cells [34]. Since fibroblasts are involved in the production of the extracellular matrix in the skin, these studies suggest that decreasing SIRT levels in aged fibroblasts may have an effect on the chronological aging processes. To take this a step further, Sharma et al. [35] found that there was a greater resistance in human dermal fibroblasts from older human subjects to reprogramming using classical Yamanaka factors, as well as higher SIRT6 levels in younger cells. However, they found that adding SIRT6 while reprogramming allowed the aged cells to have an increased reprogramming efficiency. These findings taken together suggest that both SIRT1 and SIRT6 are important molecules in skin cell aging, and warrant further exploration, especially because skin health is considered a factor representing overall "good health."

\section{The Role of Sirtuins in UV Radiation and Photoaging}

Premature development of the physiological changes observed in chronological skin aging, as well as uneven pigmentation, a deepening of wrinkles, and a rough texture, can occur as the result of the process known as photoaging $[31,32]$. Photoaging is strongly correlated with sun exposure, with both UVA (320-400 nm) and UVB $(290-320 \mathrm{~nm})$ radiation contributing to its progression [36]. Most UVB is absorbed in the epidermis, where it causes sunburn and damages cellular DNA through the formation of cyclobutane pyrimidine dimers and pyrimidine (6-4) pyrimidone photoproducts [37, 38]. DNA damage that is not adequately repaired can lead to increased cellular senescence, apoptosis, and carcinogenesis [37]. UVA penetrates more deeply into the dermal layer, damaging DNA, proteins, and lipids indirectly through the generation of reactive oxygen species (ROS), as well as breaking down collagen through the activation of the tissue-remodeling matrix metalloproteinases (MMPs) [38]. Sirtuins play a role in both UVA- and UVB-mediated events, suggesting that they could be key participants in photoaging.

SIRT1 has been shown to play a role in photoaging, especially through the inhibition of MMPs and subsequent collagen degradation. The SIRT1 activators resveratrol and metformin have been shown to inhibit MMP-9 and prevent collagen degradation when applied to human fibroblast cells or mouse skin prior to UV radiation exposure [39]. Resveratrol has similarly been shown to inhibit MMP-1 expression, whereas SIRT1 knockdown increases MMP-1 and -3 levels [40]. This protective role of SIRT1 in UV-induced photoaging has also been found in clinical samples, as SIRT1 and MMP-1 expression has been shown to increase in response to UVA radiation in 
both human skin in vivo, as well as human fibroblasts in vitro $[41,42]$. Together, this suggests that SIRT1 activators have therapeutic potential in photoaging prevention.

The case for SIRT1 involvement in UVB-mediated DNA damage has been demonstrated in several in vitro experiments using human fibroblasts. UVB radiation has been shown to decrease SIRT1 protein levels in these cells [43]. Interestingly, the natural compound juglone (5hydroxy-1,4-napthalenedione) which is found in several plants, has been shown to restore SIRT1 to normal levels after UVB treatment, suggesting that SIRT1 might play a role in preventing UVB-induced carcinogenesis [43]. Overexpressing SIRT1 in human fibroblasts reinforces this possibility, as it results in protection from UVB-induced cellular senescence and oxidative stress, presumably through the suppression of p53 acetylation [44]. However, in vivo studies show that the SIRT1 story is more complex, and the level of SIRT1 expression is critical for its role in UVB protection. Contrary to the in vitro findings in fibroblasts, keratinocyte-specific homozygous SIRT1 deletion suppresses skin cancer development in mice via p53 activation and UVB-induced apoptosis, whereas heterozygous SIRT1 deletion promotes UVB-induced skin carcinogenesis [45]. Thus, as has been seen in many of the cancer studies to date, the role of SIRT1 as a tumor promoter or suppressor in UVB-induced cancer initiation is unclear and might vary with cell/tissue type or protein levels.

Research on the role of the remaining sirtuins in UV damage response is limited. Lang et al. [46] have shown that SIRT4 levels increase in fibroblasts exposed to UVB radiation in vitro, and this correlates with an increase in cellular senescence. This finding was corroborated in vivo by an observed elevation in SIRT4 levels in naturally photoaged human skin samples [46]. Benavente et al. [47] have shown that solar simulated light (containing both UVA and UVB) induces upregulation of both SIRT 1 and 4 mRNAs, which appear to play roles in resistance to photodamage. SIRT6 has also been shown to increase in human keratinocytes in response to UVB exposure, and silencing its expression results in increased UVB-induced apoptosis in these cells [48]. This suggests that SIRTs 4 and 6 play protective roles in the UVB damage response.

\section{Connections between Oxidative Stress and Sirtuins in the Skin}

The relationship between aging and UV exposure in the skin is closely intertwined with oxidative stress, as thoroughly reviewed by Kammeyer and Luiten [37] and

Sirtuins and Skin
Rinnerthaler et al. [49]. Briefly, ROS are generated in UVA-exposed skin through the excitation of photosensitizers, which then transfer energy to molecular oxygen to produce superoxide anions, hydroxyl radicals, or singlet oxygen. These ROS have the capability to cause significant cellular damage, but also have a functional role in molecular signaling pathways. Endogenous controls for cellular damage include the conversion of ROS into less reactive species such as when superoxide dismutase reacts with superoxide anions to form hydrogen peroxide $\left(\mathrm{H}_{2} \mathrm{O}_{2}\right)$. Although $\mathrm{H}_{2} \mathrm{O}_{2}$ is less reactive than other ROS, it still has the capability to cause oxidative stress through subsequent conversion to more harmful compounds, and due to its increased stability, it is frequently used to induce oxidative stress experimentally. Studies have shown that $\mathrm{H}_{2} \mathrm{O}_{2}$-induced oxidative stress correlates with a decrease in SIRT1 levels in keratinocytes [50]. Treatment with the SIRT1 activator resveratrol has been shown to prevent $\mathrm{H}_{2} \mathrm{O}_{2}$-induced cell death, decrease proliferation, and suppress senescence, whereas the SIRT1 inhibitors sirtinol and nicotinamide enhance $\mathrm{H}_{2} \mathrm{O}_{2}$-induced cell death $[50,51]$. Keratinocytes can also be protected from $\mathrm{H}_{2} \mathrm{O}_{2}$ damage and autophagy via melatonin treatment, an effect that is reversed through SIRT1 siRNA or sirtinol treatment [52]. Together, these data suggest that SIRT1 is an active player in the prevention of $\mathrm{H}_{2} \mathrm{O}_{2}$-induced cell damage, although the mechanism is complex. Mechanistically, JNK signaling has been implicated upstream of SIRT1, and p53 has been shown to function downstream in $\mathrm{H}_{2} \mathrm{O}_{2}$-induced keratinocyte death $[50,53]$. Studies have also suggested a coordinating role between SIRT1 and AMP-activated protein kinase in the downstream activation of FOXO3 that affects $\mathrm{H}_{2} \mathrm{O}_{2}$-induced cellular senescence and proliferation, as well as interactions between SIRT1 and FOXO3a in UVB-induced oxidative stress resistance $[44,51]$. Interestingly, SIRT2 has also been shown to target FOXO3a in mouse fibroblasts, thereby regulating manganese superoxide dismutase, decreasing $\mathrm{H}_{2} \mathrm{O}_{2}$-induced ROS, and promoting cell death [54]. Thus, multiple signaling pathways and multiple sirtuins seem to be involved in the cellular response to oxidative stress in the skin.

SIRT3 has been shown to play a role in skin maintenance through oxidative stress-induced keratinocyte differentiation, a process that is crucial for skin regeneration and maintenance, and is important in skin disease. Bause et al. [55] have shown that the process is strongly linked to SIRT3 expression, as its knockdown induces differentiation through increased ROS, and increases mitochondrial superoxide generation in response to $\mathrm{H}_{2} \mathrm{O}_{2}$ treat-

Skin Pharmacol Physiol 2017;30:216-224 219 
ment. This role for SIRT3 in oxidative stress regulation might extend to stress induced by environmental stressors, as a recent study showed that ozone exposure results in decreased SIRT3 levels, correlating with increased cellular $\mathrm{H}_{2} \mathrm{O}_{2}$, reduced superoxide dismutase 2, and increased DNA damage [56]. Thus, SIRT3 may be involved in the management of oxidative stress in more than one process that is critical for normal skin maintenance.

\section{Role of Sirtuins in Wound Healing and Other Skin Diseases}

In addition to their roles in aging, UV damage, and oxidative stress, the sirtuins affect skin health in a number of different disease backgrounds. In 2013, Serravallo et al. [9] wrote a very thorough, detailed review on the topic, covering inflammatory, autoimmune, and hyperproliferative skin diseases, as well as cutaneous infections, inherited diseases, and cancer. Since then, a number of studies have expanded on the role of sirtuins in these areas.

Wound healing in the skin is impaired by knockdown or accelerated by activation of several different sirtuins. Activation of SIRTs 1, 2, and 3 through treatment with MC2562 or SIRT1 activation via resveratrol accelerates wound repair in a mouse model through increased keratinocyte proliferation [57]. In addition, SIRT1 knockdown at the wound site via shRNA results in dense, disordered collagen fibers during healing similar to those seen in hypertrophic scar formation, whereas collagen fibers similar to those seen in normal wound healing are observed after resveratrol treatment at the site [58]. SIRT6 knockdown in a diabetic mouse background further exacerbates the impaired wound healing associated with the $\mathrm{db} / \mathrm{db}$ phenotype [25]. SIRT $7^{-/-}$mice also show impaired wound healing in an otherwise wild-type background [59]. Thus, it is likely that further exploration of sirtuins could lead to new treatments for disease-induced impairment of wound healing, or aid in the minimization of scar formation.

In addition to its role in wound healing, research has recently linked SIRT1 to several different skin diseases. Its activation via resveratrol has been shown to improve psoriasis in humans [60] and an induced psoriasis-like inflammation in mice [61]. SIRT1 is downregulated in systemic sclerosis and likely plays a role in the regulation of fibroblast activation in the disease via TGF- $\beta$ signaling $[62,63]$. SIRT1 also appears to play a protective role in vitiligo [64] and aids in maintaining skin barrier integrity
[65]. These recent findings underscore the importance of sirtuins in skin diseases and provide new avenues of treatment for these common ailments. Finally, advances regarding the role of SIRT1, as well as several other sirtuins, have been made in both melanoma and nonmelanoma skin cancers (NMSCs) as discussed in the following section.

\section{Influences of Sirtuins in Skin Cancer}

Skin cancer is one of the major health problems in the world, as 3.5 million cases of NMSC are estimated to be diagnosed in 2016 in the USA alone, along with more than 76,000 cases of melanoma [66]. Melanoma develops solely from melanocytes while NMSCs arise from other cells in the skin. NMSCs such as basal cell and cutaneous squamous cell carcinomas (BCCs and SCCs, respectively) are unlikely to metastasize and can generally be removed by a dermatologist, whereas melanoma can be more dangerous because it can rapidly metastasize if not diagnosed and removed in its early stages. To date, surgical and pharmacological treatment of melanoma has not been sufficiently effective. Currently, the most widely used melanoma treatments are immunotherapy and BRAF/ MAPK pathway inhibitors $[67,68]$. While immunotherapies are quite encouraging, they are successful in only a subset of melanoma patients and are associated with the induction of autoimmune and proinflammatory side effects [68]. BRAF/MAPK pathway inhibitors fail to control melanomas in the long term, with most patients acquiring resistance after approximately 12 months of treatment and subsequent cancer recurrence (reviewed in Welsh et al. [69]). Melanoma also develops resistance to other commonly used antineoplastic agents, such as doxorubicin, that are extremely successful in other cancers. Thus, the development of novel therapeutics for melanoma treatment is critical, and sirtuins are among the proteins being investigated as potential targets in both melanoma and NMSCs.

\section{Melanoma}

Targeting sirtuins as therapeutics for melanoma treatment is complicated by the fact that sirtuins have been found to work as both tumor suppressors and promoters depending on several factors, including cell and tissue type [for reviews, see 70-73]. Research on sirtuins in melanoma is still in an early enough stage that their function as tumor suppressors or promoters cannot be defined with certainty, but studies to date support the latter. The 
first 3 studies on sirtuin function in melanoma were published concurrently in 2014. Kunimoto et al. [74] showed that SIRT1 is involved in lamellipodium extension and Akt-dependent melanoma cell migration. This could indicate potential for SIRT1 inhibition in the development of therapeutics to limit melanoma metastasis. Data from the remaining 2 studies showed SIRT1 overexpression and increased activity in melanoma cells and tissues [75, 76]. Inhibition via siRNA or tenovin-1 decreased proliferation and clonogenic survival, and increased $G_{0} / G_{1}$ cell cycle arrest and senescence-like properties, suggesting a role for SIRT1 as an oncogene. Mechanistically, MITF was shown to be an upstream regulator of SIRT1, and p53 and p21 were shown to be activated downstream upon SIRT1 inhibition. However, the network of proteins involved is complex, and a further study found that there may be a link between SIRT1 inhibition and the BUB family of cell cycle-regulating proteins [77]. This suggests that SIRT1 acts through several pathways in its promotion of cancer growth and more research into this network is needed.

Currently, limited information is available regarding the role of other sirtuins in melanoma. SIRT2 has shown potential as a regulator of several cancer progression genes in a study by Karwaciak et al. [78] and may be a good candidate for dual therapy when combined with doxorubicin as it decreases resistance to the antineoplastic agent and reduces the dosage needed for effect. Interestingly, it has recently been shown that loss of SIRT2 led to drug resistance in melanoma through BRAF and MEK inhibitors [79]. It was shown that loss of SIRT2 led to resistance of the BRAF inhibitor vemurafenib in A375 melanoma cells. In addition, inhibition of SIRT2 in melanoma was found to decrease colony formation ability. This suggests that SIRT2 may be a key contributor in the process of drug resistance in melanoma, as well as a regulator of cell growth. Taken together, these studies suggest a role for SIRT2 in melanoma progression and drug resistance.

The role of SIRT3 in melanoma has only been assessed in a recently published study from our laboratory, where we found that SIRT3 is overexpressed in both human melanoma cell lines and clinical tissue samples. Knockdown of SIRT3 in highly expressing melanoma lines via shRNA decreased cell growth and migration, colony formation, and induced senescence in vitro, as well as reduced tumor growth in a melanoma xenograft mouse model [80]. These antiproliferative changes were accompanied by a $G_{1}$ phase cell cycle arrest, as well as a decreased expression of several cyclins and cyclin-dependent kinases. Interestingly, forced overexpression of

Sirtuins and Skin
SIRT3 in a melanoma line that had lower endogenous levels of SIRT3 had the opposite impact, leading to increased proliferation. Taken together, these data suggest that SIRT3 plays an oncogenic role in melanoma. This makes it likely that targeting SIRT3, as well as the other sirtuins, may lead to potential melanoma treatments.

\section{Squamous Cell Carcinoma}

While most studies on sirtuins in skin cancer focus on melanoma, recent research has also investigated their role in skin cancer's less deadly forms. Cutaneous SCCs are generally less aggressive than melanoma but can become metastatic if left untreated [81]. Thus, new therapeutic targets are needed to counter these neoplasms. Recent research suggests that sirtuins could prove useful in this respect, as several studies support oncogenic sirtuin function in SCC. All 7 sirtuins have been shown to be overexpressed at the mRNA level in SCC tissue samples, as well as several sirtuins in an SCC cell line (A431; SIRTs 1 and 3 ) and actinic keratosis (SIRTs 2, 3, 5-7) [47]. At the protein level, overexpression of SIRT6 has also been observed, and skin-specific deletion of SIRT6 in mice inhibits skin tumorigenesis via a mechanism involving COX-2 suppression [48]. However, not all evidence supports oncogenic sirtuin function in SCC. Contrary to the findings of SIRT2 overexpression at the mRNA level, a separate study has shown that SIRT2 protein is downregulated in SCC and, further, that SIRT2 knockdown by siRNA increases the risk of cancer [82]. Thus, the role of the sirtuins in SCC of the skin is unclear, and further elucidation of the mechanisms involved is necessary to assess their potential as novel therapeutics in the treatment of SCC.

\section{Basal Cell Carcinoma}

Although it is the most common skin cancer, BCC is rarely fatal. In most cases, BCCs are successfully treated with surgery or radiation therapy. However, some patients cannot undergo these treatments for various reasons, including location and complexity of the tumor [83]. Without proper treatment, BCCs may become more aggressive, invading surrounding tissues and even metastasizing $[84,85]$. Therefore, novel molecular targets are needed to treat complex cases of BCC, and a recent study suggests sirtuins as potential candidates. The study shows expression of all 7 sirtuins in BCC patient samples, with SIRTs 2 and 3 showing downregulation relative to patient-matched normal tissue [86]. This finding suggests that SIRTs 2 and 3 may play a role in BCC pathogenesis, and further investigation could lead to their use as therapeutic targets or prognostic markers.

Skin Pharmacol Physiol 2017;30:216-224 DOI: 10.1159/000477417 


\section{Conclusion}

Since Sir2 was discovered in yeast, an abundance of research has shown a very important role of this class of HDACs in a variety of physiological functions and disease conditions. In the skin, several sirtuins have been found to play important roles in aging as well as in UV damage and oxidative stress responses. Additionally, recent research has implicated sirtuins in many skin conditions, including psoriasis and skin malignancies. Although the study of skin-based roles of sirtuins is relatively new, exploring this family of proteins may further lead to the development of novel therapeutics in skin disorders, as well as in both melanoma and NMSC management.

\section{Acknowledgments}

This work was partially supported by funding from the National Institutes of Health (R01AR059130 and R01CA176748) and the Department of Veterans Affairs (VA Merit Review Awards I01BX001008 and I01CX001441; and a Research Career Scientist Award IK6BX003780 to N.A.).

\section{Disclosure Statement}

The authors state no conflict of interest.

\section{References}

1 Liu T, Liu PY, Marshall GM: The critical role of the class III histone deacetylase SIRT1 in cancer. Cancer Res 2009;69:1702-1705.

2 Dokmanovic M, Clarke C, Marks PA: Histone deacetylase inhibitors: overview and perspectives. Mol Cancer Res 2007;5:981-989.

3 Kleszcz R, Paluszczak J, Baer-Dubowska W: Targeting aberrant cancer metabolism - the role of sirtuins. Pharmacol Rep 2015;67: 1068-1080.

4 Kim W, Kim JE: SIRT7, an emerging sirtuin: deciphering newer roles. J Physiol Pharmacol 2013;64:531-534.

5 North BJ, Marshall BL, Borra MT, Denu JM, Verdin E: The human Sir2 ortholog, SIRT2, is an NAD+-dependent tubulin deacetylase. Mol Cell 2003;11:437-444.

6 Park SH, Zhu Y, Ozden O, Kim HS, Jiang H, Deng CX, Gius D, Vassilopoulos A: SIRT2 is a tumor suppressor that connects aging, acetylome, cell cycle signaling, and carcinogenesis. Transl Cancer Res 2012;1:15-21.

7 Michan S, Sinclair D: Sirtuins in mammals: insights into their biological function. Biochem J 2007;404:1-13.

8 Haigis MC, Guarente LP: Mammalian sirtuins - emerging roles in physiology, aging, and calorie restriction. Genes Dev 2006;20:29132921.

9 Serravallo M, Jagdeo J, Glick SA, Siegel DM, Brody NI: Sirtuins in dermatology: applications for future research and therapeutics. Arch Dermatol Res 2013;305:269-282.

10 McLafferty E, Hendry C, Alistair F: The integumentary system: anatomy, physiology and function of skin. Nurs Stand 2012;27:3542.

11 Hunter HJ, Momen SE, Kleyn CE: The impact of psychosocial stress on healthy skin. Clin Exp Dermatol 2015;40:540-546

12 Holick MF: Sunlight, ultraviolet radiation, vitamin D and skin cancer: how much sunlight do we need? Adv Exp Med Biol 2014;810:116.

13 Boer M, Duchnik E, Maleszka R, Marchlewicz M: Structural and biophysical characteristics of human skin in maintaining proper epidermal barrier function. Postepy Dermatol Alergol 2016;33:1-5.

14 Sinclair DA: Toward a unified theory of caloric restriction and longevity regulation. Mech Ageing Dev 2005;126:987-1002.

15 Herranz D, Munoz-Martin M, Canamero M, Mulero F, Martinez-Pastor B, Fernandez-Capetillo O, Serrano M: Sirt1 improves healthy ageing and protects from metabolic syndrome-associated cancer. Nat Commun 2010;1:3

16 Banks AS, Kon N, Knight C, Matsumoto M, Gutierrez-Juarez R, Rossetti L, Gu W, Accili D: SirT1 gain of function increases energy efficiency and prevents diabetes in mice. Cell Metab 2008;8:333-341.

17 Bordone L, Cohen D, Robinson A, Motta MC van Veen E, Czopik A, Steele AD, Crowe $\mathrm{H}$, Marmor S, Luo J, Gu W, Guarente L: SIRT1 transgenic mice show phenotypes resembling calorie restriction. Aging Cell 2007;6:759767.

18 Satoh A, Brace CS, Rensing N, Cliften P, Wozniak DF, Herzog ED, Yamada KA, Imai S: Sirt1 extends life span and delays aging in mice through the regulation of Nk2 homeobox 1 in the DMH and LH. Cell Metab 2013; 18:416-430.

19 Kanfi Y, Shalman R, Peshti V, Pilosof SN, Gozlan YM, Pearson KJ, Lerrer B, Moazed D, Marine JC, de Cabo R, Cohen HY: Regulation of SIRT6 protein levels by nutrient availability. FEBS Lett 2008;582:543-548.

20 Longo VD: Linking sirtuins, IGF-I signaling, and starvation. Exp Gerontol 2009;44:70-74.

21 Burnett C, Valentini S, Cabreiro F, Goss M, Somogyvari M, Piper MD, Hoddinott M, Sut- phin GL, Leko V, McElwee JJ, Vazquez-Manrique RP, Orfila AM, Ackerman D, Au C, Vinti G, Riesen M, Howard K, Neri C, Bedalov A, Kaeberlein M, Soti C, Partridge L, Gems D: Absence of effects of Sir2 overexpression on lifespan in C. elegans and Drosophila. Nature 2011;477:482-485.

22 Pacholec M, Bleasdale JE, Chrunyk B, Cunningham D, Flynn D, Garofalo RS, Griffith D, Griffor M, Loulakis P, Pabst B, Qiu X, Stockman B, Thanabal V, Varghese A, Ward J, Withka J, Ahn K: SRT1720, SRT2183, SRT1460, and resveratrol are not direct activators of SIRT1. J Biol Chem 2010;285:8340-8351.

23 Baur JA: Biochemical effects of SIRT1 activators. Biochim Biophys Acta 2010;1804:16261634.

24 Dang W: The controversial world of sirtuins. Drug Discov Today Technol 2014;12:e9-e17.

25 Thandavarayan RA, Garikipati VN, Joladarashi D, Suresh Babu S, Jeyabal P, Verma SK, Mackie AR, Khan M, Arumugam S, Watanabe K, Kishore R, Krishnamurthy P: Sirtuin-6 deficiency exacerbates diabetes-induced impairment of wound healing. Exp Dermatol 2015;24:773-778.

26 Childs BG, Durik M, Baker DJ, van Deursen JM: Cellular senescence in aging and age-related disease: from mechanisms to therapy. Nat Med 2015;21:1424-1435.

27 Campisi J: Aging, cellular senescence, and cancer. Annu Rev Physiol 2013;75:685-705.

28 Passarino G, De Rango F, Montesanto A: Human longevity: genetics or lifestyle? It takes two to tango. Immun Ageing 2016;13:12.

29 Dillin A, Gottschling DE, Nystrom T: The good and the bad of being connected: the integrons of aging. Curr Opin Cell Biol 2014;26: 107-112.

30 Watroba M, Szukiewicz D: The role of sirtuins in aging and age-related diseases. Adv Med Sci 2016;61:52-62.

Garcia-Peterson/Wilking-Busch/Ndiaye/ Philippe/Setaluri/Ahmad 
31 Durai PC, Thappa DM, Kumari R, Malathi M: Aging in elderly: chronological versus photoaging. Indian J Dermatol 2012;57:343-352.

32 Richey ML, Richey HK, Fenske NA: Agingrelated skin changes: development and clinical meaning. Geriatrics 1988;43:49-52, 5759, 63-64.

33 Kalfalah F, Sobek S, Bornholz B, Gotz-Rosch C, Tigges J, Fritsche E, Krutmann J, Kohrer K, Deenen R, Ohse S, Boerries M, Busch H, Boege F: Inadequate mito-biogenesis in primary dermal fibroblasts from old humans is associated with impairment of PGC1A-independent stimulation. Exp Gerontol 2014;56: 59-68.

34 Kim KS, Park HK, Lee JW, Kim YI, Shin MK: Investigate correlation between mechanical property and aging biomarker in passaged human dermal fibroblasts. Microsc Res Tech 2015;78:277-282.

35 Sharma A, Diecke S, Zhang WY, Lan F, He C, Mordwinkin NM, Chua KF, Wu JC: The role of SIRT6 protein in aging and reprogramming of human induced pluripotent stem cells. J Biol Chem 2013;288:18439-18447.

36 Han A, Chien AL, Kang S: Photoaging. Dermatol Clin 2014;32:291-299, vii.

37 Kammeyer A, Luiten RM: Oxidation events and skin aging. Ageing Res Rev 2015;21:1629.

38 Baron ED, Suggs AK: Introduction to photobiology. Dermatol Clin 2014;32:255-266, vii.

39 Lee JS, Park KY, Min HG, Lee SJ, Kim JJ, Choi JS, Kim WS, Cha HJ: Negative regulation of stress-induced matrix metalloproteinase- 9 by Sirt1 in skin tissue. Exp Dermatol 2010;19: 1060-1066.

40 Ohguchi K, Itoh T, Akao Y, Inoue H, Nozawa Y, Ito M: SIRT1 modulates expression of matrix metalloproteinases in human dermal fibroblasts. Br J Dermatol 2010;163:689-694.

41 Niu T, Tian Y, Ren Q, Wei L, Li X, Cai Q: Red light interferes in UVA-induced photoaging of human skin fibroblast cells. Photochem Photobiol 2014;90:1349-1358.

42 Tian Y, Liu W, Niu T, Dai C, Li X, Cui C, Zhao $\mathrm{X}, \mathrm{E} \mathrm{Y,} \mathrm{Lu} \mathrm{H}$ : The injury and cumulative effects on human skin by UV exposure from artificial fluorescence emission. Photochem Photobiol 2014;90:1433-1438.

43 Wahedi HM, Lee TH, Moon EY, Kim SY: Juglone up-regulates sirt1 in skin cells under normal and UVB irradiated conditions. J Dermatol Sci 2016;81:210-212.

44 Chung KW, Choi YJ, Park MH, Jang EJ, Kim DH, Park BH, Yu BP, Chung HY: Molecular insights into SIRT1 protection against UVBinduced skin fibroblast senescence by suppression of oxidative stress and p53 acetylation. J Gerontol A Biol Sci Med Sci 2015;70: 959-968.

45 Ming M, Soltani K, Shea CR, Li X, He YY: Dual role of SIRT1 in UVB-induced skin tumorigenesis. Oncogene 2015;34:357-363.
46 Lang A, Grether-Beck S, Singh M, Kuck F, Jakob S, Kefalas A, Altinoluk-Hambuchen S, Graffmann N, Schneider M, Lindecke A, Brenden H, Felsner I, Ezzahoini H, Marini A, Weinhold S, Vierkotter A, Tigges J, Schmidt S, Stuhler K, Kohrer K, Uhrberg M, Haendeler J, Krutmann J, Piekorz RP: MicroRNA$15 \mathrm{~b}$ regulates mitochondrial ROS production and the senescence-associated secretory phenotype through sirtuin 4/SIRT4. Aging (Albany NY) 2016;8:484-509.

47 Benavente CA, Schnell SA, Jacobson EL: Effects of niacin restriction on sirtuin and PARP responses to photodamage in human skin. PLoS One 2012;7:e42276.

48 Ming M, Han W, Zhao B, Sundaresan NR, Deng CX, Gupta MP, He YY: SIRT6 promotes COX-2 expression and acts as an oncogene in skin cancer. Cancer Res 2014;74:5925-5933.

49 Rinnerthaler M, Bischof J, Streubel MK, Trost A, Richter K: Oxidative stress in aging human skin. Biomolecules 2015;5:545-589.

50 Cao C, Lu S, Kivlin R, Wallin B, Card E, Bagdasarian A, Tamakloe T, Wang WJ, Song X, Chu WM, Kouttab N, Xu A, Wan Y: SIRT1 confers protection against UVB- and $\mathrm{H}_{2} \mathrm{O}_{2}$ induced cell death via modulation of p53 and JNK in cultured skin keratinocytes. J Cell Mol Med 2009;13:3632-3643.

51 Ido Y, Duranton A, Lan F, Weikel KA, Breton L, Ruderman NB: Resveratrol prevents oxidative stress-induced senescence and proliferative dysfunction by activating the AMPKFOXO3 cascade in cultured primary human keratinocytes. PLoS One 2015;10:e0115341.

52 Lee JH, Moon JH, Nazim UM, Lee YJ, Seol JW, Eo SK, Park SY: Melatonin protects skin keratinocyte from hydrogen peroxide-mediated cell death via the SIRT1 pathway. Oncotarget 2016;7:12075-12088.

53 Johns RA: Endothelium-derived relaxing factor: basic review and clinical implications. J Cardiothorac Vasc Anesth 1991;5:69-79.

54 Wang F, Nguyen M, Qin FX, Tong Q: SIRT2 deacetylates FOXO3a in response to oxidative stress and caloric restriction. Aging Cell 2007; 6:505-514.

55 Bause AS, Matsui MS, Haigis MC: The protein deacetylase SIRT3 prevents oxidative stress-induced keratinocyte differentiation. J Biol Chem 2013;288:36484-36491.

56 McCarthy JT, Pelle E, Dong K, Brahmbhatt K, Yarosh D, Pernodet N: Effects of ozone in normal human epidermal keratinocytes. Exp Dermatol 2013;22:360-361.

57 Spallotta F, Cencioni C, Straino S, Nanni S, Rosati J, Artuso S, Manni I, Colussi C, Piaggio G, Martelli F, Valente S, Mai A, Capogrossi MC, Farsetti A, Gaetano C: A nitric oxide-dependent cross-talk between class I and III histone deacetylases accelerates skin repair. J Biol Chem 2013;288:11004-11012.

58 Bai XZ, Liu JQ, Yang LL, Fan L, He T, Su LL, Shi JH, Tang CW, Zheng Z, Hu DH: Identification of sirtuin 1 as a promising therapeutic target for hypertrophic scars. Br J Pharmacol 2016;173:1589-1601.
59 Araki S, Izumiya Y, Rokutanda T, Ianni A, Hanatani S, Kimura Y, Onoue Y, Senokuchi T, Yoshizawa T, Yasuda O, Koitabashi N, Kurabayashi M, Braun T, Bober E, Yamagata K, Ogawa H: Sirt7 contributes to myocardial tissue repair by maintaining transforming growth factor-beta signaling pathway. Circulation 2015;132:1081-1093.

60 Krueger JG, Suarez-Farinas M, Cueto I, Khacherian A, Matheson R, Parish LC, Leonardi C, Shortino D, Gupta A, Haddad J, Vlasuk GP, Jacobson EW: A randomized, placebocontrolled study of SRT2104, a SIRT1 activator, in patients with moderate to severe psoriasis. PLoS One 2015;10:e142081.

61 Kjaer TN, Thorsen K, Jessen N, Stenderup K, Pedersen SB: Resveratrol ameliorates imiquimod-induced psoriasis-like skin inflammation in mice. PLoS One 2015;10:e126599.

62 Wei J, Ghosh AK, Chu H, Fang F, Hinchcliff ME, Wang J, Marangoni RG, Varga J: The histone deacetylase sirtuin 1 is reduced in systemic sclerosis and abrogates fibrotic responses by targeting transforming growth factor beta signaling. Arthritis Rheumatol 2015;67:1323-1334.

63 Zerr P, Palumbo-Zerr K, Huang J, Tomcik M, Sumova B, Distler O, Schett G, Distler JH: Sirt1 regulates canonical TGF-beta signalling to control fibroblast activation and tissue fibrosis. Ann Rheum Dis 2016;75:226-233.

64 Becatti M, Fiorillo C, Barygina V, Cecchi C, Lotti T, Prignano F, Silvestro A, Nassi P, Taddei N: SIRT1 regulates MAPK pathways in vitiligo skin: insight into the molecular pathways of cell survival. J Cell Mol Med 2014;18: 514-529.

65 Ming M, Zhao B, Shea CR, Shah P, Qiang L, White SR, Sims DM, He YY: Loss of sirtuin 1 (SIRT1) disrupts skin barrier integrity and sensitizes mice to epicutaneous allergen challenge. J Allergy Clin Immunol 2015;135:936945 e934.

66 Siegel RL, Miller KD, Jemal A: Cancer statistics, 2016. CA Cancer J Clin 2016;66:7-30.

67 Shelledy L, Roman D: Vemurafenib: first-inclass BRAF-mutated inhibitor for the treatment of unresectable or metastatic melanoma. J Adv Pract Oncol 2015;6:361-365.

68 Kaufman HL, Kirkwood JM, Hodi FS, Agarwala S, Amatruda T, Bines SD, Clark JI, Curti B, Ernstoff MS, Gajewski T, Gonzalez R, Hyde LJ, Lawson D, Lotze M, Lutzky J, Margolin K, McDermott DF, Morton D, Pavlick A, Richards JM, Sharfman W, Sondak VK, Sosman J, Steel S, Tarhini A, Thompson JA, Titze J, Urba W, White R, Atkins MB: The Society for Immunotherapy of Cancer consensus statement on tumour immunotherapy for the treatment of cutaneous melanoma. Nat Rev Clin Oncol 2013;10:588-598.

69 Welsh SJ, Rizos H, Scolyer RA, Long GV: Resistance to combination BRAF and MEK inhibition in metastatic melanoma: where to next? Eur J Cancer 2016;62:76-85. 
70 Wilking MJ, Ahmad N: The role of SIRT1 in cancer: the saga continues. Am J Pathol 2015; 185:26-28.

71 Chen Y, Fu LL, Wen X, Wang XY, Liu J, Cheng Y, Huang J: Sirtuin-3 (SIRT3), a therapeutic target with oncogenic and tumor-suppressive function in cancer. Cell Death Dis 2014;5:e1047.

72 Stunkel W, Campbell RM: Sirtuin 1 (SIRT1): the misunderstood HDAC. J Biomol Screen 2011;16:1153-1169.

73 Fang Y, Nicholl MB: Sirtuin 1 in malignant transformation: friend or foe? Cancer Lett 2011;306:10-14.

74 Kunimoto R, Jimbow K, Tanimura A, Sato M, Horimoto K, Hayashi T, Hisahara S, Sugino T, Hirobe T, Yamashita T, Horio Y: SIRT1 regulates lamellipodium extension and migration of melanoma cells. J Invest Dermatol 2014;134:1693-1700.

75 Wilking MJ, Singh C, Nihal M, Zhong W, Ahmad N: SIRT1 deacetylase is overexpressed in human melanoma and its small molecule inhibition imparts anti-proliferative response via p53 activation. Arch Biochem Biophys 2014;563:94-100.

76 Ohanna M, Bonet C, Bille K, Allegra M, Davidson I, Bahadoran P, Lacour JP, Ballotti $\mathrm{R}$, Bertolotto C: SIRT1 promotes proliferation and inhibits the senescence-like phenotype in human melanoma cells. Oncotarget 2014;5: 2085-2095.

77 Singh CK, George J, Nihal M, Sabat G, Kumar $\mathrm{R}$, Ahmad N: Novel downstream molecular targets of SIRT1 in melanoma: a quantitative proteomics approach. Oncotarget 2014;5: 1987-1999.

78 Karwaciak I, Gorzkiewicz M, Ryba K, Dastych J, Pulaski L, Ratajewski M: AC-93253 triggers the downregulation of melanoma progression markers and the inhibition of melanoma cell proliferation. Chem Biol Interact 2015;236: 9-18.
79 Bajpe PK, Prahallad A, Horlings H, Nagtegaal I, Beijersbergen R, Bernards R: A chromatin modifier genetic screen identifies SIRT2 as a modulator of response to targeted therapies through the regulation of MEK kinase activity. Oncogene 2015;34:531-536.

80 George J, Nihal M, Singh CK, Zhong W, Liu $\mathrm{X}$, Ahmad N: Pro-proliferative function of mitochondrial sirtuin deacetylase SIRT3 in human melanoma. J Invest Dermatol 2016; 136:809-818.

81 Lazareth V: Management of non-melanoma skin cancer. Semin Oncol Nurs 2013;29:182194.

82 Ming M, Qiang L, Zhao B, He YY: Mammalian SIRT2 inhibits keratin 19 expression and is a tumor suppressor in skin. Exp Dermatol 2014;23:207-209.

83 Mohan SV, Chang AL: Advanced basal cell carcinoma: epidemiology and therapeutic innovations. Curr Dermatol Rep 2014;3:40-45.

84 Maroun C, Alam E, Khalifeh I, Abbas O, Moukarbel RV: Nasal basal cell carcinoma with matrical differentiation: risk of metastasis and impact on management. Head Neck Pathol 2017;11:228-233.

85 Lear JT, Corner C, Dziewulski P, Fife K, Ross GL, Varma S, Harwood CA: Challenges and new horizons in the management of advanced basal cell carcinoma: a UK perspective. $\mathrm{Br} \mathrm{J}$ Cancer 2014;111:1476-1481.

86 Temel M, Koc MN, Ulutas S, Gogebakan B: The expression levels of the sirtuins in patients with BCC. Tumour Biol 2016;37:64296435.

87 Li L, Shi L, Yang S, Yan R, Zhang D, Yang J, He L, Li W, Yi X, Sun L, Liang J, Cheng Z, Shang Y, Yu W: SIRT7 is a histone desuccinylase that functionally links to chromatin compaction and genome stability. Nat Commun 2016;7:12235.

88 Seidel J, Klockenbusch C, Schwarzer D: Investigating deformylase and deacylase activity of mammalian and bacterial sirtuins. Chembiochem 2016;17:398-402.

89 Liszt G, Ford E, Kurtev M, Guarente L: Mouse Sir2 homolog SIRT6 is a nuclear ADP-ribosyltransferase. J Biol Chem 2005;280:2131321320.
90 Jiang H, Khan S, Wang Y, Charron G, He B, Sebastian C, Du J, Kim R, Ge E, Mostoslavsky R, Hang HC, Hao Q, Lin H: SIRT6 regulates TNF-alpha secretion through hydrolysis of long-chain fatty acyl lysine. Nature 2013;496: 110-113.

91 Teng YB, Jing H, Aramsangtienchai P, He B, Khan S, Hu J, Lin H, Hao Q: Efficient demyristoylase activity of SIRT2 revealed by kinetic and structural studies. Sci Rep 2015;5:8529.

92 Bao X, Wang Y, Li X, Li XM, Liu Z, Yang T, Wong CF, Zhang J, Hao Q, Li XD: Identification of "erasers" for lysine crotonylated histone marks using a chemical proteomics approach. Elife 2014;3:e02999.

93 Haigis MC, Mostoslavsky R, Haigis KM, Fahie K, Christodoulou DC, Murphy AJ, Valenzuela DM, Yancopoulos GD, Karow M, Blander G, Wolberger C, Prolla TA, Weindruch R, Alt FW, Guarente L: SIRT4 inhibits glutamate dehydrogenase and opposes the effects of calorie restriction in pancreatic beta cells. Cell 2006;126:941-954.

94 Mathias RA, Greco TM, Oberstein A, Budayeva HG, Chakrabarti R, Rowland EA, Kang Y, Shenk T, Cristea IM: Sirtuin 4 is a lipoamidase regulating pyruvate dehydrogenase complex activity. Cell 2014;159:16151625.

95 Tan M, Peng C, Anderson KA, Chhoy P, Xie Z, Dai L, Park J, Chen Y, Huang H, Zhang Y, Ro J, Wagner GR, Green MF, Madsen AS, Schmiesing J, Peterson BS, Xu G, Ilkayeva OR, Muehlbauer MJ, Braulke T, Muhlhausen C, Backos DS, Olsen CA, McGuire PJ, Pletcher SD, Lombard DB, Hirschey MD, Zhao Y: Lysine glutarylation is a protein posttranslational modification regulated by SIRT5. Cell Metab 2014;19:605-617.

96 Du J, Zhou Y, Su X, Yu JJ, Khan S, Jiang H, Kim J, Woo J, Kim JH, Choi BH, He B, Chen W, Zhang S, Cerione RA, Auwerx J, Hao Q, Lin $\mathrm{H}$ : Sirt5 is a NAD-dependent protein lysine demalonylase and desuccinylase. Science 2011;334:806-809. 